\title{
Effect of acetone vapor treatment on photoluminescence of porous $\mathrm{nc}-\mathrm{Si}-\mathrm{SiO}_{\mathrm{x}}$ nanostructures
}

\author{
I.Z. Indutnyi, K.V. Michailovska, V.I. Min’ko, P.E. Shepeliavyi \\ V. Lashkaryov Institute of Semiconductor Physics, NAS of Ukraine \\ 41, prospect Nauky, 03028 Kyiv, Ukraine \\ E-mail: indutnyy@isp.kiev.ua
}

\begin{abstract}
The effect of treatment in saturated acetone vapors on the spectral composition and intensity of photoluminescence (PL) in porous oblique deposited $\mathrm{SiO}_{\mathrm{x}}$ films is studied. As a result of this treatment followed by high-temperature annealing at the temperature $930{ }^{\circ} \mathrm{C}$, considerable PL intensity growth and the small blueshift of PL peak position are observed in the porous, column-like structure films containing $\mathrm{Si}$ nanocrystals. A more intense shortwave band (peak position - 540-560 nm) appears in the PL spectrum of these structures, in addition to the longwave band (760-780 nm). Both PL bands in treated samples are characterized by monomolecular radiative recombination, which can be attributed to annihilation of excitons in silicon nanocrystals embedded into oxide matrix (longwave band) and in carbon-enriched matrix near surface of oxide nanocolumns (shortwave band). The possibility to control the PL characteristics of the porous structures in a wide spectral range by above treatment is shown.
\end{abstract}

Keywords: nanocrystals, silicon oxide, photoluminescence, thin film.

Manuscript received 13.01.09; accepted for publication 18.03.09; published online 20.03.09.

\section{Introduction}

Recently, fabrication of Si-based light emitting materials has been a very active area of research stimulated by its potential application in Si-based optoelectronic devices. Since the discovery of visible photoluminescence (PL) in porous silicon [1], efficient room-temperature PL has been realized in several nanometer-sized Si materials [26]. Recent investigations were focused on Si-rich dielectric thin films (mainly $\mathrm{SiO}_{\mathrm{x}}$ ) made by techniques compatible with the microelectronic industry. To fabricate these films, a few basic techniques are usually used: plasma-enhanced deposition, ion implantation, laser ablation, magnetron sputtering, evaporation in vacuum, etc. All these methods allow to fabricate films with required $x$, and then the $\mathrm{SiO}_{\mathrm{x}}$ layers are annealed at high temperature. As a result, $\mathrm{Si}$ nanoclusters $1-5 \mathrm{~nm}$ in size are formed in the oxide matrix. The structure of the nanoparticles depends on the annealing temperature: annealing at temperatures below $900{ }^{\circ} \mathrm{C}$ results in formation of amorphous inclusions, whereas at higher temperatures, the $\mathrm{Si}$ nanocrystals are formed, with the electronic structure modified by the quantum-confinement effect [2, 4-6]. With decreasing dimensions of the nanoclusters, the peak of the emission spectrum shifts to shorter wavelengths.

In the previous study [7], we suggested method of controlling the dimensions of $\mathrm{Si}$ nanoparticles in the oxide matrix, namely, the use of oblique deposition of $\mathrm{Si}$ monoxide thermally evaporated in vacuum. During such deposition, $\mathrm{SiO}_{\mathrm{x}}$ films with a porous (column-like) structure are formed. The thermally stimulated formation of Si nanoinclusions in such films occurs in a restricted volume of the $\mathrm{SiO}_{x}$ columns with a small diameter. These results in the formation of small-sized silicon nanoclusters (nc-Si) compared to the clusters formed in continuous films of the same composition. In this case, we observe a broadening and a shift of the PL band to longer wavelengths in the spectrum.

One of the most important factors influencing the characteristics of $\mathrm{PL}$ is the state of the $\mathrm{Si}-\mathrm{SiO}_{\mathrm{x}}$ interface. The $\mathrm{Si}-\mathrm{SiO}_{\mathrm{x}}$ interface can be modified by adsorption of the compounds of necessary composition. The adsorption is most efficient in porous structures at enhanced pressure and temperature. In this paper, we report the results of studying the effect of treatment in acetone vapors (carboncontaining compounds) on PL of the porous nc-Si-SiO structures produced by oblique deposition. 


\section{Experiment}

The samples were produced by thermal evaporation of Cerac Inc. silicon monoxide (with $99.9 \%$ purity) in vacuum (the residual pressure was $(1-2) \times 10^{-3} \mathrm{~Pa}$ ).

As substrates, we used two-sided polished $\mathrm{Si}$ wafers. During deposition, the substrates were oriented at the angles $\beta=0^{\circ}, 60^{\circ}$ and $75^{\circ}$ between the normal to the substrate surface and the direction to the evaporator.

The thickness of the films were monitored in situ by the quartz-crystal-oscillator monitor system (KIT-1) and measured after deposition by a microinterferometer (MII-4). The thickness of normally deposited films was equal to $250-350 \mathrm{~nm}$, for oblique deposited films - 400$700 \mathrm{~nm}$

Some of the $\mathrm{SiO}_{\mathrm{x}}$ samples (except for the reference ones) were kept for two hours in the pressure-tight autoclave that contained the certain amount of acetone $\left(\mathrm{CH}_{3} \mathrm{COCH}_{3}\right)$ at the temperature $200{ }^{\circ} \mathrm{C}$, here the pressure of acetone vapors in autoclave was $18 \mathrm{~atm}$. Then all the samples were annealed in vacuum at the temperature $930{ }^{\circ} \mathrm{C}$ for $15 \mathrm{~min}$ to produce nanocrystalline silicon inclusions in the oxide matrix [3]. Some of the reference samples were treated in acetone vapors after annealing.

The PL spectra were recorded at room temperature using a system based on a ZMR-3 monochromator. The PL signal was excited by radiation of an $\mathrm{N}_{2}$ laser at the wavelength $337 \mathrm{~nm}$ and violet light-emitting diode EDEV-1LA1 (wavelength $400 \mathrm{~nm}$ ) which was used for measurements of PL intensity dependence on the excitation power. The signal was detected using a FEU-51 photomultiplier, and PL spectra were normalized to the spectral sensitivity of the experimental system. SEM apparatus (ZEISS EVO 50XVP) was used to observe the cross-section of annealed samples. Selective etching of $\mathrm{nc}-\mathrm{Si}-\mathrm{SiO}_{\mathrm{x}}$ samples was conducted in a weak solution of hydrofluoric acid.

\section{Results and discussion}

In Fig. 1, cross-sectional views of $\mathrm{SiO}_{\mathrm{x}}$ films oblique deposited on silicon wafer are shown, where Fig. 1a shows SEM micrograph of the sample deposited at $\beta=75^{\circ}$, and Fig. $1 \mathrm{~b}-$ sample deposited at $\beta=60^{\circ}$. As can be seen in this figure, the investigated $\mathrm{SiO}_{\mathrm{x}}$ films have a porous (inclined column-like) structure with the column diameters of 10-100 $\mathrm{nm}$. An angle of column inclination, their dimensions and volume of pores in the structure of films depend on the deposition angle. The porosity of these samples (volume share of pores) were measured in the previous paper [8], and it was equal to 34 and $53 \%$ for the samples deposited at $\beta=60^{\circ}$ and $75^{\circ}$, accordingly. High-temperature annealing of oblique deposited $\mathrm{SiO}_{\mathrm{x}}$ films do not change porosity and column-like structure of the samples.

The composition of the films (the parameter $x$ ) was determined using compositional dependence of the position of the basic IR band peak in spectra of $\mathrm{SiO}_{\mathrm{x}}$
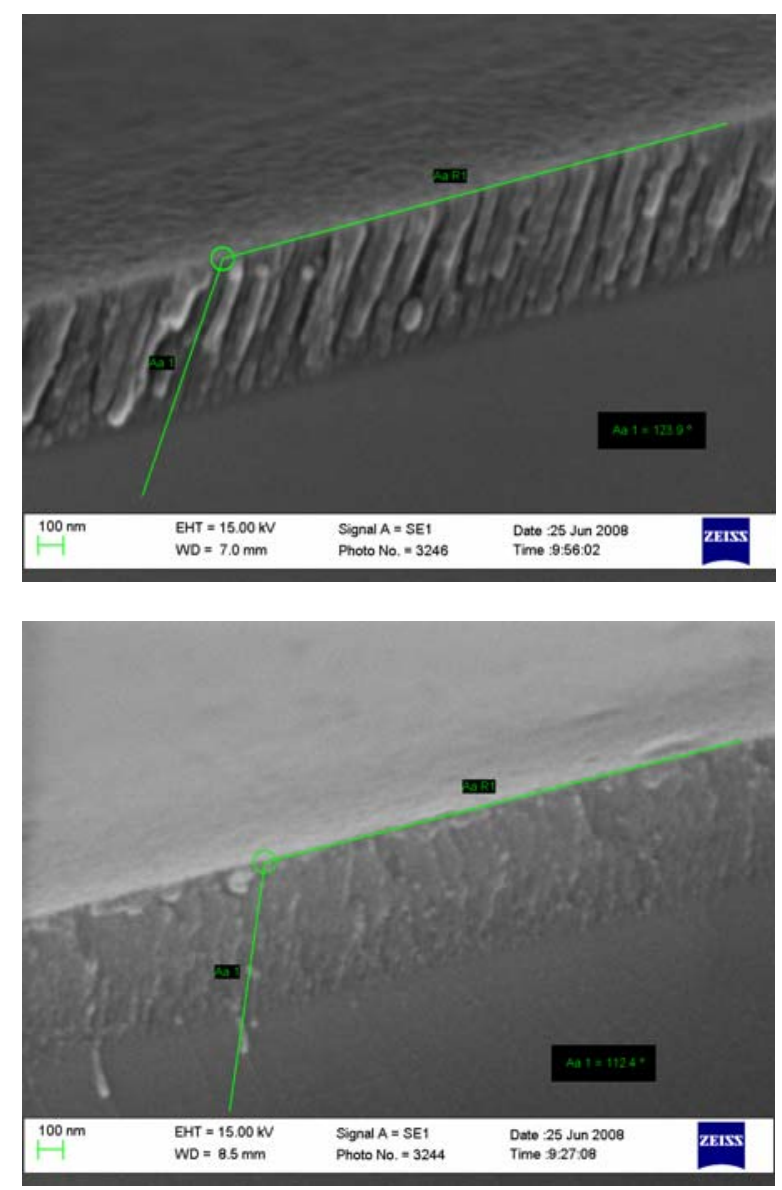

Fig. 1. $\mathrm{SEM}$ micrographs of $\mathrm{SiO}_{\mathrm{x}}$ film cross-section: (a) for the samples deposited at $\beta=75^{\circ}$, and (b) for that deposited at $\beta=60^{\circ}$.

layers within the range $1000-1100 \mathrm{~cm}^{-1}$, as established in [9]. This band corresponds to the transverse stretching vibrations of the bridge-coordinated oxygen atoms ( $\mathrm{Si}-$ $\mathrm{O}-\mathrm{Si}$ stretching mode). Since only the vibrations in the silicon-oxygen phase are active in this spectral range, while the $\mathrm{Si}-\mathrm{Si}$ bond vibrations cannot be recorded, this method can be used to determine the composition of the oxide matrix in both as-prepared and annealed samples containing the silicon phase. The stoichiometric parameter $x$ determined by this method is 1.42 and 1.51 for the samples deposited at the angles $60^{\circ}$ and $75^{\circ}$, respectively [7]. The difference in chemical composition is related to the porosity of the films, as described previously $[7,8]$. During annealing, the $\mathrm{SiO}_{x}$ oxide is layered into $\mathrm{Si}$ and $\mathrm{SiO}_{2}$, and the stoichiometric parameter of the oxide matrix (determined from the IR spectra) is $x \approx 1.9$ for all the samples.

Fig. 2 shows the PL spectra of two annealed porous samples deposited at the angle $60^{\circ}$, namely, the reference sample (curve a) and the sample treated in acetone vapors in the autoclave before annealing (curve b). It can be seen that for the untreated (reference) sample two broad PL bands are observed. One, more intensive with a maximum at $\sim 780 \mathrm{~nm}$ and second,

(C) 2009, V. Lashkaryov Institute of Semiconductor Physics, National Academy of Sciences of Ukraine 


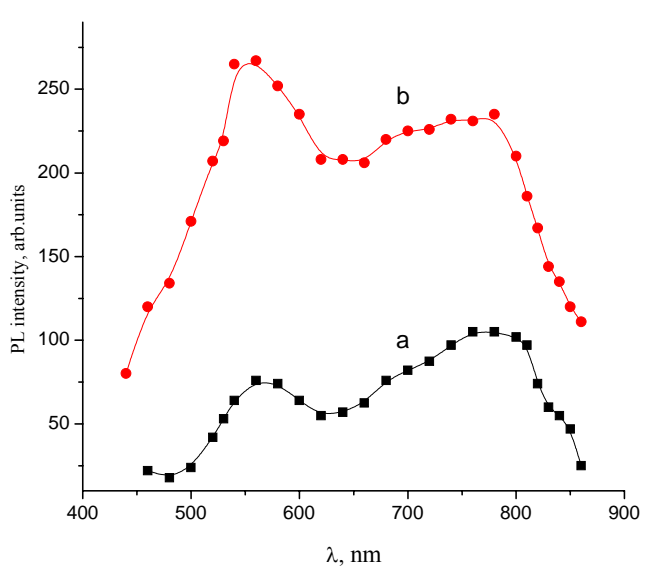

Fig. 2. PL spectra of annealed $\mathrm{SiO}_{\mathrm{x}}$ samples deposited at the angle $60^{\circ}$ : the reference sample (a) and that treated in acetone vapors in autoclave before annealing (b). Both samples were annealed in vacuum at $930{ }^{\circ} \mathrm{C}$ for $15 \mathrm{~min}$.

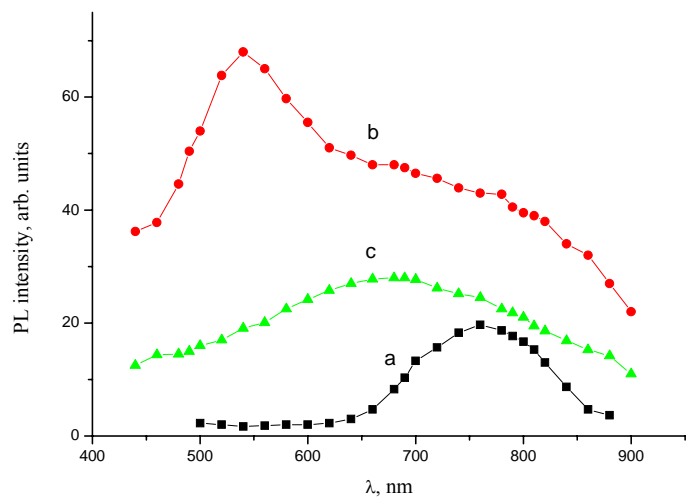

Fig. 3. PL spectra of annealed $\mathrm{SiO}_{\mathrm{x}}$ samples deposited at the angle $75^{\circ}$ : the reference sample (a), the sample treated in acetone vapors in autoclave before annealing (b), and the sample after etching in $0.1 \%$ solution of HF during $20 \mathrm{~s}(\mathrm{c})$. The samples were annealed in vacuum at $930^{\circ} \mathrm{C}$ for $15 \mathrm{~min}$.

considerably less intensive, is in a visible range of spectrum (maximum at $\sim 560 \mathrm{~nm}$ ). The intense longwave band that appears in the PL spectrum is connected with the quantum-confinement effect of nc-Si, which appeared in the matrix of oxide during the high temperature annealing of $\mathrm{SiO}_{\mathrm{x}}$ films $[10,11]$. The shortwave band is determined, to our opinion, by radiative recombination of excited charges on the surface defects of oxide nanocolumns. In PL spectra of continuous non-porous $\mathrm{nc}-\mathrm{Si}-\mathrm{SiO}_{\mathrm{x}}$ structures deposited at $\beta=0^{\circ}$, this band in the PL spectrum is absent, which confirms our supposition.

After treatment in the autoclave before annealing (curve b) two bands in PL spectrum are also observed. But the intensity of both bands increase, more considerably for the shortwave one. The peak of the shortwave band is shifted to shorter wavelengths slightly - to $550 \mathrm{~nm}$. This band is more intense than the longwave one, and longwave band becomes more wide and asymmetric, with a peak in the range of 750-770 $\mathrm{nm}$.

PL spectra of obliquely deposited at the angle $75^{\circ}$ samples non-treated (curve a), treated in autoclave (b) and both annealed at $930{ }^{\circ} \mathrm{C}$ are shown in Fig. 3. It can be seen that for the untreated (reference) sample a broad PL band is observed with a peak at $\sim 760 \mathrm{~nm}$, which can be connected also with the quantum-confinement effect and exciton annihilation in nc-Si that appear during annealing of $\mathrm{SiO}_{\mathrm{x}}$ film (curve a). The shortwave band is not observed by contrast to the spectrum in Fig. 2 (curve a). The samples deposited at the angle $75^{\circ}$ have higher porosity than deposited at $\beta=60^{\circ}$. It can result in a higher concentration of non-radiative recombination centers on the surface of oxide nanocolumns. The nonradiative recombination quenches the radiative recombination of excited charge carriers near the surface of oxide nanocolumns that explains absence of the shortwave band.

Treatment in the autoclave before high-temperature annealing causes noticeable changes in PL spectra of these samples. The PL intensity grows significantly, too. In the visible range of spectrum, an intensive band appears with a maximum near $540 \mathrm{~nm}$. The unstructured PL spectrum, which can be interpreted as superposition of a few bands corresponding to various sizes of $\mathrm{nc}-\mathrm{Si}$, is observed in IR region.

Analysis of PL spectra of obliquely deposited at the angles $75^{\circ}$ and $60^{\circ}$ samples shows that treatment in the autoclave before annealing at high temperatures causes similar changes of the spectra. These changes are characterized by growth of the PL intensity, appearance of an intense band in the visible range of spectrum and a small blue shift of the bands.

Some of the samples were treated in the autoclave by using acetone vapors after high-temperature annealing. This treatment does not induce any noticeable changes in the intensity, shape, or position of the bands in the PL spectrum.

Using a light-emitting diode EDEV-1LA1 $(400 \mathrm{~nm})$ for PL excitation, we explored the dependence of PL intensity on the intensity of excitation. Fig. 4 shows the dependence of PL intensity taken at the peak $(760 \mathrm{~nm})$ of infrared emission (curve b) and at the peak of shortwave $(540 \mathrm{~nm})$ band (curve a) for the sample obliquely deposited at the angle $75^{\circ}$ and treated in the autoclave. It can be seen that the PL intensity for both bands grows linearly with increasing in the intensity of excitation.

The linear dependence between intensities of luminescence and excitation has been obtained theoretically in the work [12], where the mechanism of exciton recombination in nanocrystals was investigated. It indicates that both PL bands of the treated samples can be related with the quantum-confinement effect and exciton annihilation in nc-Si. 


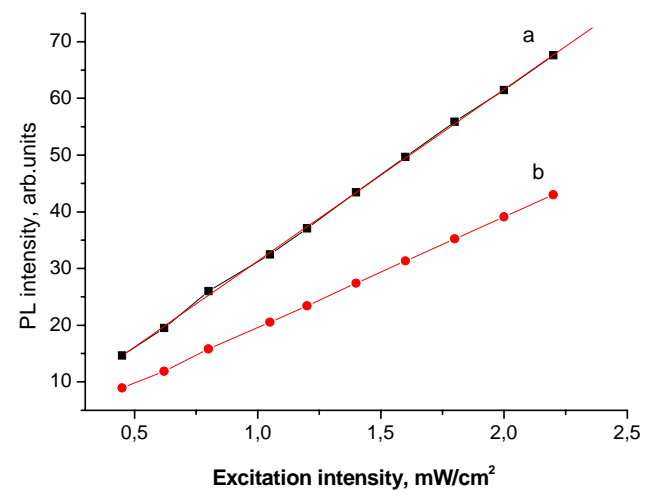

Fig. 4. Dependence of the PL intensity on the excitation intensity for $\mathrm{SiO}_{\mathrm{x}}$ film obliquely deposited at the angle $75^{\circ}$ and treated in the autoclave. PL intensity at the peak $(760 \mathrm{~nm})$ of the infrared emission(b) and at the peak of shortwave (540 $\mathrm{nm}$ ) band (a).

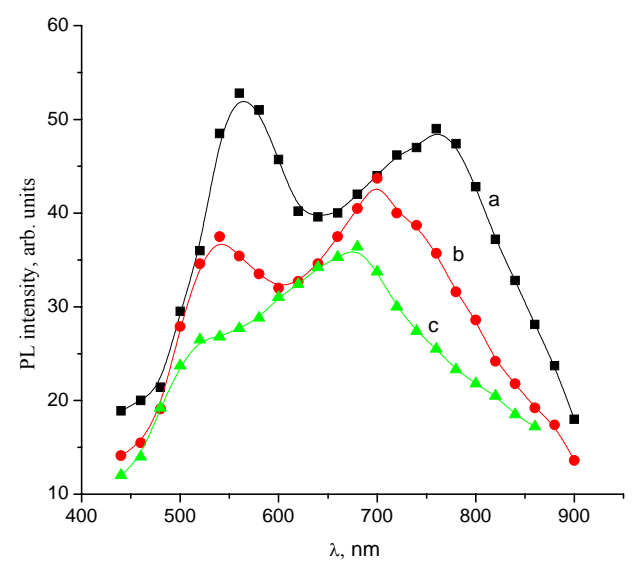

Fig. 5. PL spectra of the sample obliquely deposited at the angle $60^{\circ}$ and treated in the autoclave before (a), and after etching in $1 \%$ solution of HF during $20 \mathrm{~s}$ (b) and $40 \mathrm{~s}$ (c).

The second confirmation of this assumption is the dependence of PL maxima of both bands on the content of silicon in deposited $\mathrm{SiO}_{\mathrm{x}}$ films. The sample deposited at the angle $60^{\circ}$ contains much silicon than deposited at the angle $75^{\circ}(x=1.42$ and 1.51 [7]). During the high temperature annealing, in the first film larger nc-Si are formed, and PL maximum shifts to longer wavelengths (780 and $760 \mathrm{~nm}$ for the samples, deposited at $60^{\circ}$ and $75^{\circ}$, accordingly). The spectral position of shortwave PL bands that appear in the treated films also correlate with the content of silicon in initial layers $(560$ and $540 \mathrm{~nm}$, accordingly).

With the purpose to more definitively determine the origin of shortwave bands, we investigated the influence of the selective etching on the PL spectra of the autoclave-treated $\mathrm{nc}-\mathrm{Si}-\mathrm{SiO}_{\mathrm{x}}$ samples. The etching of the samples was performed in weak $(0.1-1 \%)$ water solutions of $\mathrm{HF}$ at room temperature. As known, HF solution dissolves $\mathrm{SiO}_{2}$, while the rate of $\mathrm{SiC}$ and $\mathrm{Si}$ dissolution in HF solutions is very small [13].

Fig. 5 shows PL spectra of the sample obliquely deposited at the angle $60^{\circ}$ and treated in the autoclave before etching (curve a), and after etching in $1 \%$ solution of $\mathrm{HF}$ for 20 and $40 \mathrm{~s}$ (curves $\mathrm{b}$ and c, accordingly). It can be seen that etching of the sample results in gradual lowering the PL intensity in all the spectral range, more actively in its shortwave region. The maximum of the longwave PL band gradually shifts to shorter wavelengths, the shortwave PL band shifts and disappears. After etching for $40 \mathrm{~s}$ in the PL spectrum, one wide band is presented with its peak at $680 \mathrm{~nm}$.

The similar result has been obtained for the samples obliquely deposited at the angle $75^{\circ}$, treated and annealed in the same conditions. In the PL spectrum of these samples after etching in $0.1 \%$ solution of HF, one wide band is present with the peak at $670-675 \mathrm{~nm}$ (Fig. 3, curve c). The intensity of this PL band is considerably less than before etching (Fig. 3, curve b).

The shortwave shift of PL bands and decrease in their intensity as a result of etching is possible to be explained by dissolution of $\mathrm{SiO}_{2}$ layer on surface of oxide nanocolumns and following oxidation of silicon atoms on nc-Si surface. It results in the decreasing nc-Si size, and the PL band is shifted to the shortwave side. Fast diminishing and disappearance of the shortwave PL band shows that this band is related with the radiative centers or nc-Si, which located near the surface of oxide nanocolumns and can be removed under dissolution of the surface $\mathrm{SiO}_{2}$ layer.

Appearance of the intense shortwave band after barometric treatment in acetone vapors can be caused by an effect of carbon impurities. It was shown [14] that, at high temperatures $\left(750-900{ }^{\circ} \mathrm{C}\right)$, acetone reacts with the silicon surface, which results in formation of the $\mathrm{SiC}_{\mathrm{x}}$ layer. Introduction of a considerable amount of carbon into the oxide matrix containing Si nanocrystals provides a means for noticeable shifting the PL spectrum to shorter wavelengths [15]. Therefore, our results may be interpreted similarly to that done in [15]: during annealing, the adsorbed acetone reacts with the silicon nanocrystals (in the small-sized oxide columns and near the surface of the columns) to form $\mathrm{SiC}_{\mathrm{x}}$ surrounding of these nanocrystals, which results in the shift of the PL spectrum to shorter wavelengths. Since the modification of nanocrystals with adsorbed molecules in the course of annealing occurs at the surface of the columns, the nc$\mathrm{Si}$-matrix interface is modified first for those nanocrystals that are formed in columns smaller in diameter or located near the surface of the columns. Nanocrystals formed in the bulk of larger columns remain surrounded by the oxide. Therefore, the PL spectrum exhibits two bands: one, at longer wavelengths, corresponds to nanocrystals in the oxide matrix, and the other, at shorter wavelengths, to nc-Si in Si-C surrounding.

Another possible mechanism of appearance of the shortwave PL band is thermostimulated formation of the 
local radiative centers on the surface of oxide nanocolumns. During annealing, carbon can form the $\mathrm{Si}=\mathrm{C}, \mathrm{Si}-\mathrm{C}$ or $\mathrm{O}-\mathrm{Si}-\mathrm{C}$ bonds. These bonds provide effective luminescent centers and passivate the interface between Si core and surrounding oxide. Except for it, the substantial increase the PL intensity after barometric treatment of investigated samples is well explained by passivation of broken silicon bonds on the nc-Si surface.

\section{Conclusions}

In this study, SEM measurements show that obliquely deposited at the angle $75^{\circ}$ and $60^{\circ} \mathrm{SiO}_{\mathrm{x}}$ films have porous column-like structure, porosity of which depends on the angle of deposition. The effect of barometric processing these films in acetone vapors before hightemperature $\left(930^{\circ} \mathrm{C}\right)$ annealing on the light-emission characteristics of nc- $\mathrm{Si}-\mathrm{SiO}_{\mathrm{x}}$ structures is examined. It is ascertained that, as a result of this treatment, the increase in the PL intensity, the small blueshift of PL peak position are observed, and a more intense shortwave band (peak position - 540-560 nm) appears in the PL spectrum of these structures, in addition to longwave band $(760-780 \mathrm{~nm})$. For both bands the position of maxima depends on the composition of initial layers (content of silicon in $\mathrm{SiO}_{\mathrm{x}}$ film), which depends on the angle of deposition.

Both PL bands in treated samples are characterized by monomolecular radiative recombination, which can be attributed to annihilation of excitons in silicon nanocrystals embedded into oxide matrix (longwave band), and in nc-Si in carbon-enriched matrix near the surface of oxide nanocolumns (shortwave band). The effect of selective etching on the PL spectra of the autoclave-treated $\mathrm{nc}-\mathrm{Si}-\mathrm{SiO}_{\mathrm{x}}$ samples has confirmed the assumption that the intense shortwave band appearing after treatment is related with the radiative centers or nanocrystals located near the surface of oxide nanocolumns.

Thus, the barometric treatment of porous oxide layers in acetone vapors at elevated temperatures is an efficient method that provides means to increase the PL intensity of $\mathrm{nc}-\mathrm{Si}-\mathrm{SiO}_{\mathrm{x}}$ structures and to vary the spectral composition of emission over a wide spectral region.

\section{References}

1. L.T. Canham, Silicon quantum wire array fabrication by electrochemical and chemical dissolution of wafers // Appl. Phys. Lett. 57, p. 1046-1048 (1990).

2. M. Molinary, H. Rinnert and H. Vergnat, Visible photoluminescence in amorphous $\mathrm{SiO}_{x}$ thin films prepared by silicon evaporation under a molecular oxygen atmosphere // Appl. Phys. Lett. 82, p. 3877 3879 (2003).

3. V.Ya. Bratus', V.A. Yukhimchuk, L.I. Berezhinsky et al., Structural transformations and silicon nanocrystallite formation in $\mathrm{SiO}_{x}$ films // Semiconductors 35(7), p. 821-826 (2001).

4. D. Nesheva, C. Raptis, A. Perakis et al., Raman scattering and photoluminescence from $\mathrm{Si}$ nanoparticles in annealed $\mathrm{SiO}_{\mathrm{x}}$ thin films // J. Appl. Phys. 92, p. 4678-4683 (2002).

5. 4. I.P. Lisovskyy, I.Z. Indutnyy, B.N. Gnennyy et al., Structural and phase changes in $\mathrm{SiO}_{\mathrm{x}}$ films under thermal vacuum treatments// Fizika $i$ Tekhnika Poluprovodnikov 37, p. 98-103 (2003) (in Russian) [Semiconductors 37, p. 97 (2003)].

6. B.G. Fernandez, M. Lopez, C. Garcia et al., Influence of average size and interface passivation on the spectral emission of Si nanocrystals embedded in $\mathrm{SiO}_{\mathrm{x}} / /$ J. Appl. Phys. 89, p. 237-243 (2001).

7. I.Z. Indutnyy, I.Yu. Maidanchuk, V.I. Min'ko, Visible photoluminescence from annealed porous $\mathrm{SiO}_{\mathrm{x}}$ films // J. Optoelectron. and Adv. Mater. 7, p. 1231-1236 (2005).

8. V.A. Dan'ko, I.Z. Indutnyy, I.Y. Maidanchuk et al., Formation of the photoluminescence structure based on $\mathrm{SiO}_{\mathrm{x}}$ porous films // Optoelectronika $i$ poluprovodnikovaya tekhnika 39, p. 65-72 (2004) (in Ukrainian).

9. M. Nakamura, Y. Mochizuki, K. Usami et al., Infrared absorption spectra and compositions of evaporated silicon oxide $\left(\mathrm{SiO}_{\mathrm{x}}\right)$ // Solid State Communs 50, p. 1079-1081 (1984).

10. S.V. Svechnikov, E.B. Kaganovich, Luminescent properties of $\mathrm{Si}$ nanostructures (review) // Optoelectronika i poluprovodnikovaya tekhnika 39, p. 5-26 (2004) (in Ukrainian).

11. I.Z. Indutnyy, I.Yu. Maidanchuk, V.I. Min'ko et al., Effect of chemical treatment on photoluminescence spectra of $\mathrm{SiO}_{\mathrm{x}}$ layers containing $\mathrm{Si}$ nanoparticles // Fizika i Tekhnika Poluprovodnikov 41 (10), p. 1265-1271 (2007) (in Russian).

12. P.K. Kashkarov, B.V. Kamenev, E.A. Konstantinova et al., Dynamics of noneqilibrium charge carriers in silicon quantum wires // Uspekhi fizicheskikh nauk 168 (5), p. 577-582 (1998).

13. G. Wilieke, K. Kellermann // Semicond. Sci. Technol. 11, p. 415-420 (1996).

14. T. Takami, S. Ishidzuka, Y. Igari, H. Range, I. Kusunoki, Reaction of $\mathrm{Si}(111)$ surface with acetone // Thin Solid Films 376, p. 89-98 (2000).

15. S.Y. Seo, K.S. Cho, J.H. Shin, Intense blue-white luminescence from carbon-doped silicon-rich silicon oxide // Appl. Phys. Lett. 84, p. 717-719 (2004). 